\title{
Glycemic control and its impact on oxidative stress biomarkers in type 2 diabetic patients treated with metformin: a cross-sectional analysis
}

\author{
Controle glicêmico e seu impacto em biomarcadores de estresse oxidativo em \\ pacientes diabéticos tipo 2 tratados com metformina: uma análise transversal
}

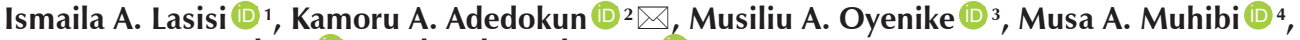

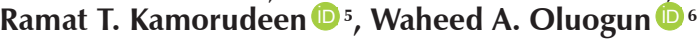 \\ 1 Laboratory Unit, Health Centre, Osun State Polytechnic Iree, Osun State, Nigeria. \\ 2 Department of Oral Pathology, King Saud University Medical City, DUH, Riyadh, Saudi Arabia; Department of Chemical Pathology, College of Medicine, \\ University of Ibadan, Ibadan, Oyo State, Nigeria. \\ 3 Department of Medical Laboratory Science, Faculty of Health Science, Ladoke Akintola University of Technology, Osogbo, Osun State, Nigeria. \\ ${ }^{4}$ Department of Medical Laboratory Science, Edo State University, Iyamho, Edo State, Nigeria. \\ Department of Infant Welfare, General Hospital, Asubiaro, Osogbo, Osun State, Nigeria. \\ ${ }^{6}$ Department of Morbid Anatomy and Histopathology, Ladoke Akintola University of Technology Teaching Hospital, Osogbo, Osun State, Nigeria.
}

How to cite this article:

Lasisi IA, Adedokun KA, Oyenike MA, Muhibi MA, Kamorudeen RT, Oluogun WA. Glycemic control and its impact on oxidative stress biomarkers in type 2 diabetic patients treated with metformin: a cross-sectional analysis. Sci Med. 2019;29(2):ID33630. http:// doi.org/10.15448/1980-6108.2019.2.33630.

\section{ABSTRACT}

AIMS: Evidence shows that diabetic patients may be predisposed to oxidative stress owing to increased glyco-oxidation and lipid peroxidation processes in consequence of chronic hyperglycemia. However, there is dearth of information whether glycemic control positively affects the antioxidant defense system in type 2 diabetes mellitus (T2DM). We investigated the potential association between glycemic control and oxidative stress biomarkers in controlled and uncontrolled diabetic states.

METHODS: After obtaining ethical clearance, we included patients receiving metformin with glycated hemoglobin Alc $<7.0 \%$ (glycemic control); newly diagnosed T2DM patients without glycemic control with hemoglobin A1c $>7.0 \%$; and apparently healthy normoglycemic individuals. The following biomarkers were determined: fasting glycemia level, malondialdehyde, glutathione peroxidase activity, catalase activity, total antioxidant capacity and total cholesterol level. The comparisons between the groups were made by ANOVA.

RESULTS: The participants were 260 in number: 80 with controlled diabetes, 80 uncontrolled and 100 controls. All participants were between 40 and 71 years old. Fasting glycemia level and hemoglobin A1c showed significant reductions $(\mathrm{p}<0.05)$ in controlled T2DM against the uncontrolled T2DM group, all the same both were significantly higher $(\mathrm{p}<0.05)$ against the controls. Likewise, malondialdehyde levels showed significant elevations $(\mathrm{p}<0.05)$ correspondingly in both uncontrolled and controlled T2DM against the controls, accompanied with significant reductions $(\mathrm{p}<0.05)$ in the antioxidative enzyme activities (glutathione peroxidase activity and catalase activity) and total antioxidant capacity levels against the controls. In addition, total cholesterol was significantly reduced $(\mathrm{p}<0.05)$ in controlled T2DM against both uncontrolled T2DM and controls, respectively. There were significant correlations between hemoglobin A1c and oxidative stress biomarkers ( $\mathrm{p}<0.05)$.

CONCLUSION: There was no remarkable difference in oxidative stress states between glycemic controlled and uncontrolled T2DM, despite differences in their fasting glycemia and glycated hemoglobin levels. Our data, therefore, suggest that chronic hyperglycemia and possibly anti-diabetic medication may both equally associate with oxidative stress.

KEYWORDS: antioxidant capacity; chronic hyperglycemia; glycated hemoglobin; glycemic control; lipid peroxidation; metformin; oxidative stress; type 2 diabetes mellitus.

\section{RESUMO}

OBJETIVOS: Evidências mostram que pacientes diabéticos podem estar predispostos ao estresse oxidativo devido ao aumento dos processos de oxidação da glicose e peroxidação lipídica em consequência da hiperglicemia crônica. No entanto, há escassez de informações se o controle glicêmico afeta positivamente o sistema de defesa antioxidante no diabetes mellitus tipo 2. Esse estudo investiga a possível associação entre controle glicêmico e biomarcadores de estresse oxidativo em estados glicêmicos controlados e não controlados.

MÉTODOS: Após a liberação da comissão de ética, o estudo incluiu pacientes em uso de medicação hipoglicemiante (metformina) com hemoglobina glicosilada A1c $<7,0 \%$ (diabetes controlado), pacientes recém-diagnosticados com diabetes mellitus tipo 2 sem controle glicêmico e com hemoglobina A1c $>7,0 \%$ e indivíduos normoglicêmicos aparentemente saudáveis. Foram determinados os seguintes biomarcadores: glicemia de jejum, malonaldeído, atividade da glutationa peroxidase, atividade de catalase, capacidade antioxidante total e nível de colesterol total. A comparação entre os grupos foi feita pela ANOVA 
RESULTADOS: Foram incluídos 260 participantes: 80 com diabetes controlada, 80 não controlada e 100 controles. Todos os participantes tinham entre 40 e 71 anos. A glicemia de jejum e a hemoglobina glicosilada foram significativamente menores ( $<<0,05$ ) nos diabéticos controlados comparado aos não controlados, e todos os diabéticos apresentaram valores significativamente maiores ( $\mathrm{p}<0,05)$ que os controles. Da mesma forma, os níveis de malonaldeído foram significativamente maiores $(\mathrm{p}<0,05)$ nos diabéticos (controlados e não controlados), assim como valores das atividades antioxidantes (glutationa peroxidase e catalase) e nos níveis de capacidade antioxidante foram significativamente menores $(p<0,05)$ frente aos controles. Além disso, o colesterol total foi significativamente menor $(p<0,05)$ nos diabéticos controlados quando comparados aos não controlados e controles, respectivamente. Houve correlações significativas entre a hemoglobina glicosilada e do estresse oxidativo $(\mathrm{p}<0,05)$.

CONCLUSÃO: Não houve diferença significativa nos estados de estresse oxidativo entre os diabéticos controlados e não controlados, apesar das diferenças nos níveis de glicose plasmática e hemoglobina glicosilada. Nossos dados, portanto, sugerem que a hiperglicemia crônica e, possivelmente, a medicação antidiabética pode associar-se igualmente ao estresse oxidativo.

DESCRITORES: capacidade antioxidante; hiperglicemia crônica; hemoglobina glicada; controle glicêmico; peroxidação lipídica; metformina; estresse oxidativo; diabetes mellitus tipo 2.

Abbreviation: CAT, catalase activity; FG, fasting glycemia level; GSH-Px, Glutathione peroxidase; HbA1c, glycated hemoglobin A1c; MDA, malondialdehyde; ROS, reactive oxygen species; T2DM, type 2 diabetes mellitus;TAC, total antioxidant capacity; TC: total cholesterol.

\section{INTRODUCTION}

In type 2 diabetes mellitus (T2DM), hyperglycemia is repeatedly associated with elevated production of reactive oxygen species (ROS) in consequence of glyco-oxidation that may ultimately lead to lipid peroxidative reaction [1]. Further, systemic ROS level also increases in the course of protein glycosylation and may result in high blood superoxide level [1] under several alternative glucose metabolic pathways [2]. Besides, there is compelling evidence that hyperglycemia has high tendency to induce diabetic complications via increased ROS production because of potential oxidative stress response [3]. In the meantime, previous report suggests that glycemic control via alteration of metabolic route often termed as "dangerous metabolic route in diabetes" involving modulation in the diacylglycerol-protein kinase $\mathrm{C}$ pathway may down regulate pro inflammatory cytokines may result in diminution of ROS production [3]. In this regard, ROS production through glycemic control may play a pivotal role in preventing diabetic complications [4].

Although, report shows that optimal glycemic control, defined as glycated hemoglobin A1c (HbA1c) $\leq 7 \%$, results in a lower incidence of microvascular complications in diabetes mellitus $[4,5]$, there is paucity of data concerning the effect of glycemic control against probable development of oxidative stress that has been attributed with a number of potential complications. We therefore investigated association between glycemic control and biomarkers of oxidative stress in both controlled and uncontrolled glycemic states.

\section{METHODS}

Ethical clearance was obtained from the Ethics Committees of Ladoke Akintola University of Technology Teaching Hospital Osogbo, Osun State, Nigeria, before the study commenced. Patients were recruited at the State Hospital Asubiaro and Ladoke Akintola University of Technology Teaching Hospital, both located in Osogbo, Osun State, Nigeria.

The participants included were 80 consecutive patients with $\mathrm{HbA} 1 \mathrm{c}$ who were regularly attending outpatient clinic and placed on range of hypoglycemic medication containing metformin (controlled T2DM) with monitoring record of $\mathrm{HbA} 1 \mathrm{c}<7.0 \%$. Other patients' group involved 80 clinically and newly diagnosed T2DM patients without medication and with $\mathrm{HbA} 1 \mathrm{c}>7.0 \%$ (uncontrolled T2DM). In addition, 100 apparently healthy normoglycemic individuals were recruited as controls from the general population. All participants had ages ranged 40-71 years.

The study included patients that fulfilled the American Diabetes Association diagnostic criteria [7] and who were within the age range of 18 to 60 years that had been diagnosed of or placed on therapy for T2DM not less than three months preceding the recruitment period. The smokers, alcoholics and participants with the history of recent allergic reactions or other chronic diseases were excluded in the study.

The subjects were instructed to avoid any foods or drinks (except water) commencing from 8:00pm overnight prior to blood collection. After an overnight fasting, $10 \mathrm{~mL}$ of venous blood $(5 \mathrm{~mL}$ into lithium heparin; $3 \mathrm{~mL}$ into fluoride oxalate and $2 \mathrm{~mL}$ into plain non-anticoagulant bottles) was collected from 
the antecubital vein. The blood was allowed to stand in an upright position briefly on the bench and then centrifuged at $2500 \mathrm{rpm}$ for 10 minutes. Fasting plasma glucose was measured immediately while other plasma and serum were then stored at $-20^{\circ} \mathrm{C}$ until the time of analyses. All other analyses were measured within three months of blood collection. The values of glycated hemoglobin were documented.

The glucose assay was performed based on enzyme colorimetric method. In this method, glucose was oxidized by glucose oxidase to gluconic acid and hydrogen peroxide. In the presence of peroxidase, the hydrogen peroxide reacted with 4-amino antipyrine and N-ethyl-N-sulfopropyl-m-toluidine to form violetcoloured quinoneimine precipitate and measured at $520 \mathrm{~nm}$ [8].

Glycated hemoglobin was estimated using immunoturbidimetric latex method with commercial kit from Randox Laboratories Ltd (Diamond Road, Crumlin, Co. Antrim, Ireland). The method utilized the interaction of antigen and antibody that directly determined A1c in whole blood based on agglutination reaction [9].

Level of lipid peroxidation was determined by measuring the formation of malondialdehyde (MDA), a product of lipid peroxidation, using the method of Varshney and Kale [10]. MDA was produced from peroxidation of membrane fatty acid reacted with 2-thiobarbituric acid chromogenic reagent under acidic conditions and yielded a pink-coloured complex measured spectrophotometrically at $532 \mathrm{~nm}$.

Glutathione peroxidase (GSH-Px) was determined when the oxidation of glutathione was converted to reduced form by cumene hydroperoxide reagent in the presence of glutathione reductase and NADPH, with concormitant oxidation of NADPH to $\mathrm{NADP}^{+}[11]$. Absorbance of colour changes was measured at $340 \mathrm{~nm}$. Glutathione peroxidase concentration was determined multiplying absorbance/min by a factor of 8412 .

Catalase activity (CAT) was assayed by measuring decreasing peroxide amount/amount of product formed following Aebi method [12]. One international unit (IU) of catalase represented the enzyme which decomposed one microlitre of peroxidase per minute at $25^{\circ} \mathrm{C}$. Absorbance of test at $240 \mathrm{~nm}$ was measured by spectrophotometer.

Total antioxidant capacity (TAC) was determined using the ferric reducing/antioxidant power [13]. $1.5 \mathrm{~mL}$ of working pre-warmed $37^{\circ} \mathrm{C}$ ferric reducing/ antioxidant power reagent $(300 \mathrm{mM}$ acetate buffer $\mathrm{pH} 3.6 ; 10 \mathrm{Mm}$ 2,4,6-tripyridyl-s-triazine in $40 \mathrm{mM}$ hydrochloric acid and $20 \mathrm{Mm}$ ferric chloride at ratio $10: 1: 1)$ was vortex mixed with $50 \mu \mathrm{L}$ of test sample and standards. Absorbance was read at $593 \mathrm{~nm}$ against a reagent blank. The result was reported as $\mu$ mol Trolox equiv./L.

Total cholesterol (TC) was determined after enzymatic hydrolysis and oxidation. Reaction of hydrogen peroxide and 4-aminoantipyrine in the presence of phenol and peroxidase formed an indicator coloured-complex, quinoneimine, which was measured spectrophotometrically at 546nm [14].

The sample size was determined for a desired confidence level of 0.05 and 1.96 confidence interval, considering a prevalence rate of $4.6 \%$ of the T2DM in the south-west Nigeria obtained from the recent literature [6]. The minimum sample size calculated for each group was 67 . The study data were statistically analyzed using the SPSS for Windows program-version 10.0 (Chicago, IL. USA). The data were expressed as mean and standard deviation. The data followed Gaussian's distribution; between-group comparisons were assessed for nominal variables with the $\chi^{2}$-square test, while analysis of variance and post hoc for multiple comparisons were used to compare the quantitative variables. Statistical significance was assessed at $\mathrm{p}<0.05$. Pearson's correlation was employed in testing associations between the variables, consecutively. All calculated P-values were two-tailed.

\section{RESULTS}

The mean fasting plasma glucose (FPG) and $\mathrm{HbA} 1 \mathrm{c}$ values in controlled T2DM, uncontrolled T2DM, and normoglycemic control groups were presented in Table 1. There were significant differences $(p<0.001)$ comparing mean FPG and $\mathrm{HbA} 1 \mathrm{c}$ values in controlled T2DM group against both uncontrolled T2DM and the control groups among male, female and general populations, respectively.

In Table 2, some selected biomarkers of oxidative stress in controlled T2DM against uncontrolled T2DM and control groups were presented. There was no significant difference $(p>0.05)$ in mean MDA values between controlled and uncontrolled T2DM groups, while both were significantly increased $(p<0.001)$ compared to the controls, similarly among the male, female and general populations, respectively. However, a gender difference between the two groups of T2DM was noted. There was a significant reduction $(p<0.001)$ when the male group of controlled T2DM was compared against the same sex of uncontrolled T2DM group. 
Table 1. The mean fasting plasma glucose and glycated hemoglobin values for controlled and uncontrolled diabetes groups and control groups*

\begin{tabular}{|c|c|c|c|c|}
\hline & $\begin{array}{l}\text { Uncontrolled T2DM } \\
\qquad(\mathrm{n}=\mathbf{8 0})\end{array}$ & $\begin{array}{l}\text { Controlled T2DM } \\
\qquad(\mathbf{n = 8 0})\end{array}$ & $\begin{array}{l}\text { Controls } \\
(n=100)\end{array}$ & $p$ value \\
\hline Male, n (\%) & $46(57.5)$ & $50(62.5)$ & $50(50.0)$ & 0.23 \\
\hline Age (years) & $57 \pm 12$ & $58 \pm 13$ & $55 \pm 15$ & 0.65 \\
\hline \multicolumn{5}{|l|}{ Glucose $(\mathrm{mmol} / \mathrm{L})$} \\
\hline General population & $9.86 \pm 1.13^{a, b}$ & $5.86 \pm 1.24 \mathrm{a}$ & $3.72 \pm 0.75$ & $<0.001$ \\
\hline Male & $9.87 \pm 1.14^{\mathrm{a}, \mathrm{b}}$ & $5.58 \pm 1.16^{\mathrm{a}}$ & $3.92 \pm 0.85$ & $<0.001$ \\
\hline Female & $9.43 \pm 1.15^{\mathrm{a}, \mathrm{b}}$ & $6.14 \pm 1.32^{a}$ & $3.52 \pm 1.10$ & $<0.001$ \\
\hline \multicolumn{5}{|c|}{ Glycated haemoglobin (\%) } \\
\hline General population & $8.86 \pm 0.44^{a, b}$ & $5.71 \pm 0.47^{a}$ & $5.01 \pm 0.40$ & $<0.001$ \\
\hline Male & $8.75 \pm 0.46^{\mathrm{a}, \mathrm{b}}$ & $5.68 \pm 0.50^{\mathrm{a}}$ & $5.05 \pm 0.40$ & $<0.001$ \\
\hline Female & $9.04 \pm 0.34^{\mathrm{a}, \mathrm{b}}$ & $5.74 \pm 0.43^{\mathrm{a}}$ & $4.97 \pm 0.38$ & $<0.001$ \\
\hline
\end{tabular}

* The data were expressed as mean \pm standard deviation.

a significantly different from healthy controls (Post hoc); ${ }^{b}$ significantly different from controlled T2DM (Post hoc).

T2DM: type 2 diabetes mellitus.

Table 2. Biochemical parameters of oxidative stress in controlled and uncontrolled diabetes groups against control group*

\begin{tabular}{|c|c|c|c|c|c|c|}
\hline & $\mathbf{n}$ & $\begin{array}{c}\mathrm{MDA} \\
(\mu \mathrm{mol} / \mathrm{L})\end{array}$ & $\begin{array}{l}\text { GSH-Px } \\
(\mathrm{U} / \mathrm{L})\end{array}$ & $\begin{array}{l}\text { CAT } \\
(\mathrm{U} / \mathrm{L})\end{array}$ & $\begin{array}{c}\text { TAC } \\
(\mu \text { mol Trolox equiv./L) }\end{array}$ & $\begin{array}{c}\mathrm{TC} \\
(\mathrm{mmol} / \mathrm{L})\end{array}$ \\
\hline \multicolumn{7}{|l|}{ General population } \\
\hline Uncontrolled T2DM & 80 & $6.68 \pm 0.82^{a}$ & $5656.55 \pm 1511.31^{a, b}$ & $166.83 \pm 50.79^{a}$ & $990.87 \pm 93.05^{a}$ & $3.45 \pm 0.65^{b}$ \\
\hline Controlled T2DM & 80 & $6.51 \pm 0.72^{a}$ & $6591.05 \pm 1181.02^{\mathrm{a}}$ & $176.37 \pm 52.30^{\mathrm{a}}$ & $964.88 \pm 86.51^{a}$ & $3.13 \pm 0.37^{a}$ \\
\hline Controls & 100 & $5.45 \pm 0.96$ & $8844.18 \pm 1175.65$ & $282.63 \pm 54.74$ & $1334.85 \pm 104.88$ & $3.31 \pm 0.43$ \\
\hline $\mathrm{p}$-value & & $<0.001$ & $<0.001$ & 0.001 & 0.001 & 0.569 \\
\hline \multicolumn{7}{|l|}{ Male population } \\
\hline Uncontrolled T2DM & 50 & $6.73 \pm 0.07^{\mathrm{a}, \mathrm{b}}$ & $5495.76 \pm 1335.72^{a, b}$ & $155.60 \pm 58.80^{\mathrm{a}}$ & $993.20 \pm 99.37^{a, b}$ & $3.21 \pm 0.64^{b}$ \\
\hline Controlled T2DM & 46 & $6.48 \pm 0.07^{a}$ & $6870.74 \pm 1034.70^{a}$ & $169.65 \pm 49.21^{a}$ & $932.12 \pm 73.69^{a}$ & $2.98 \pm 0.35^{a}$ \\
\hline Controls & 50 & $5.20 \pm 0.09$ & $9214.35 \pm 1246.46$ & $333.25 \pm 19.65$ & $1272.95 \pm 84.20$ & $3.15 \pm 0.36$ \\
\hline $\mathrm{p}$-value & & $<0.001$ & $<0.001$ & 0.001 & 0.001 & 0.015 \\
\hline \multicolumn{7}{|l|}{ Female population } \\
\hline Uncontrolled T2DM & 30 & $6.60 \pm 0.99^{a}$ & $5924.53 \pm 1783.56^{a}$ & $185.53 \pm 25.64^{a}$ & $987.00 \pm 84.66^{a}$ & $3.86 \pm 0.43^{a, b}$ \\
\hline Controlled T2DM & 30 & $6.54 \pm 0.75^{a}$ & $6212.65 \pm 1289.64^{a}$ & $185.47 \pm 56.44^{a}$ & $1009.18 \pm 84.56^{a}$ & $3.32 \pm 0.31^{a}$ \\
\hline Controls & 30 & $5.69 \pm 0.96$ & $8474.00 \pm 997.44$ & $232.00 \pm 19.19$ & $1396.75 \pm 86.16$ & $3.47 \pm 0.45$ \\
\hline$p$-value & & $<0.001$ & $<0.001$ & 0.001 & 0.001 & 0.015 \\
\hline
\end{tabular}

* The data were expressed as mean \pm standard deviation.

a significantly different from healthy controls (POst hoc); ${ }^{\mathrm{b}}$ significantly different from controlled diabetic group (Post hoc).

CAT: catalase activity; GSH-Px: glutathione peroxidase; MDA: malondialdehyde; T2DM: type 2 diabetes mellitus; TC: total cholesterol; TAC: total antioxidant capacity.

In addittion, the mean activity of GSH-Px in controlled T2DM subjects were significantly higher $(\mathrm{p}<0.001)$ compared to that of uncontrolled T2DM patients, while both were significantly lower $(\mathrm{p}<0.001)$ compared to the controls. In the same way, a gender difference was noted; there was a significant reduction $(p<0.001)$ when the male group of controlled T2DM was compared against the same gender of uncontrolled T2DM group.

Furthermore, there were significant reductions $(p<0.001)$ comparing mean CAT in all population categories (male, female and general populations) of controlled and uncontrolled T2DM groups against the controls. Conversely, this enzyme activity showed no significant difference $(p>0.05)$ between controlled T2DM and uncontrolled T2DM groups.

In addition, there was no significant difference $(p>0.05)$ in mean TAC values between controlled and uncontrolled T2DM groups in female and the general populations, while there was a significant reduction $(\mathrm{p}<0.001)$ in the male category of controlled T2DM. In addition, there were significant reductions $(p<0.001)$ comparing TAC mean values in all populations (male, female and general populations) of both controlled and uncontrolled T2DM groups against the controls. 
Table 3. Correlation between glycated hemoglobin and oxidative stress parameters in controlled and uncontrolled type 2 diabetes patients

\begin{tabular}{|c|c|c|c|c|c|c|c|c|c|c|c|c|}
\hline & \multicolumn{2}{|c|}{$\begin{array}{l}\text { Glucose } \\
(\mathrm{mmol} / \mathrm{l})\end{array}$} & \multicolumn{2}{|c|}{$\begin{array}{c}\text { MDA } \\
(\mu \mathrm{mol} / \mathrm{L})\end{array}$} & \multicolumn{2}{|c|}{$\begin{array}{l}\text { GSH-Px } \\
\text { (U/L) }\end{array}$} & \multicolumn{2}{|c|}{$\begin{array}{l}\text { CAT } \\
(\mathrm{U} / \mathrm{L})\end{array}$} & \multicolumn{2}{|c|}{$\begin{array}{c}\text { TAC } \\
(\mu \mathrm{mol} \text { Trolox equiv./L) }\end{array}$} & \multicolumn{2}{|c|}{$\begin{array}{c}\mathrm{TC} \\
(\mathrm{mmol} / \mathrm{L})\end{array}$} \\
\hline & $\mathbf{r}$ & $\mathbf{p}$ & $\mathbf{r}$ & $\mathbf{p}$ & $\mathbf{r}$ & $\mathbf{p}$ & $\mathbf{r}$ & $\mathbf{p}$ & $\mathbf{r}$ & $\mathbf{p}$ & $\mathbf{r}$ & $\mathbf{p}$ \\
\hline Uncontrolled T2DM & 0.747 & 0.005 & 0.728 & 0.007 & -0.620 & 0.031 & -0.663 & 0.019 & -0.684 & 0.014 & 0.820 & 0.001 \\
\hline Controlled T2DM & 0.992 & $<0.001$ & 0.943 & $<0.001$ & -0.962 & $<0.001$ & 0.940 & $<0.001$ & -0.183 & 0.050 & 0.938 & $<0.001$ \\
\hline
\end{tabular}

r: correlation coefficient; p: significant level.

CAT: catalaseactivity; GSH-Px: glutathione peroxidase; HbA1c: glycated hemoglobin A1c; MDA: malondialdehyde; T2DM: type 2 diabetes mellitus; TAC: total antioxidant capacity; TC: total cholesterol.

Similarly, there were significant increases $(\mathrm{p}<0.001)$ comparing mean TC in all population categories (male, female and general populations) in uncontrolled T2DM group against the controlled T2DM group. Conversely, there were no significant differences $(p>0.05)$ in TC levels between uncontrolled T2DM and the controls, except in female population category where a significant increase $(p<0.05)$ was observed.

Table 3 shows correlations between $\mathrm{HbAlc}$ and FPG, biomarkers of oxidative stress, and TC levels in both controlled and uncontrolled T2DM. There were statistically significant positive correlations between HbAlc and FPG, MDA, as well as TC levels in both controlled and uncontrolled T2DM, respectively. In contrast, negative correlations were observed between HbA1c and GSH-Px, TAC and CAT levels in both controlled and uncontrolled T2DM, correspondingly. However, the correlation between $\mathrm{HbAlc}$ and TAC in controlled T2DM was not statistically signicant, while other negative correlations were statistically significant.

\section{DISCUSSION}

There is a dearth of knowledge to show whether glycemic control helps ameliorating or reversing the effect of possible oxidative stress and potential diabetic complications. In this study, we investigated association between glycemic control and oxidative stress biomarkers (MDA, GSH-Px, CAT and TAC) in both controlled and uncontrolled type 2 diabetes (T2DM). The values of FPG, HbA1c and the biomarkers of oxidative stress were considerably altered.

We observed remarkable increases in FPG and HbA1c levels both in controlled and uncontrolled T2DM against the controls. Nevertheless, patients on hypoglycemic treatment (controlled T2DM) had reduced FPG and $\mathrm{HbA} 1 \mathrm{c}$ levels against the uncontrolled counterpart (Table 1). In addition, there was a strong association between FPG and HbA1c levels, regardless of glycemic control or not (Table 3). Our findings agree with the data from earlier studies $[15,16]$. Meanwhile, a detailed review of mechanistic effect of hyperglycemia implicates potential over production of NADH and mitochondrial ROS that ultimately inhibit glyceraldehyde 3-phosphate dehydrogenase activity in glycolytic pathway. Consequently, inhibition of GAPDH triggers the alternative glucose metabolic (shunt/minor) pathways whose activities are normally negligible under euglycemic glycolytic pathway, but in turn generates ROS in chronic hyperglycemia thus aggravating cellular oxidative stress [17]. Again, apart from hyperglycemia-mediated induction of alternative pathways, the process of glycation (formation of $\mathrm{HbA1c}$ ) has been associated with significant ROS production in diabetes [18].

In addition, the present study showed increased MDA levels in both controlled and uncontrolled T2DM against the euglycemic individuals. Meanwhile, MDA is an established indicator of lipid peroxidation in the process of building up oxidative stress [1]. An increase in plasma concentration of MDA level in T2DM patients, controlled and uncontrolled as shown in this study, clearly reflects oxidative stress in consequence of lipid peroxidation. In concordance with the present study, Mishra and Mishra [19] reported a positive correlation between MDA level and indices of glycemic control. In the present study, comparison between controlled T2DM against uncontrolled T2DM showed no significant difference in mean plasma level of MDA. This may be an indication of oxidative stress in diabetic patients exposed to hypoglycemic medication akin to the resultant chronic hyperglycemic effect in diabetic patients. Our findings therefore show that glycemic control may not prevent lipid peroxidation. Again, we hypothesize that some hypoglycemic agents may not prevent oxidative changes by normalization of hyperglycemia but rather serve as a possible trigger for marked lipid peroxidation in a controlled diabetic state. Our assumptions are supported by a previous study 
where it was demonstrated that, in T2DM induction of oxidative stress is largely influenced not only by hyperglycemia but also by the various classes of antidiabetic therapeutic agents [20].

Besides, although GSH-Px activity in uncontrolled T2DM patients was considerably lower against the controlled T2DM, nevertheless GSH-Px activities in both controlled and uncontrolled DM were appreciably low against individuals in euglycemic state. This indicated that there were reduced scavenging capacities of antioxidant defense system against increased free radicals, possibly owing to glucose autoxidation, which might lead to elevation of lipid peroxidation as earlier suggested by Aouacheri et al. [21]. Further, in tandem with the present study, report shows that while GSH level reduces, cellular antioxidant capacity becomes potentially compromised yielding elevated levels of ROS that are detrimental to physiologically active macromolecules and induce oxidative damage involving [17].

Moreover, the present study also showed considerable reductions in catalase activities correspondingly in both controlled T2DM and uncontrolled T2DM patients, as opposed to normal individuals. This observation is in conformity with the previous study where low catalase activity was associated with diabetes [22]. We suggest that catalase activity could be because of enhanced production of superoxide anion radical and hydrogen peroxide, which might be in consequence of increased glucose concentration in the plasma, as above reported. Our view is supported by the report of Phaniendra and coworkers [23], where superoxide anion radical is reported as an inhibitor of catalase activity while hydrogen peroxide suggested as an established precursor of other ROS, both associated with initiation and propagation processes involving lipid peroxidation. In addition, impact of catalase antioxidant failure has long been reported in T2DM [22]. Mechanistically, chronic hyperglycemia (a hallmark of T2DM) is an endogenous stimulus that induces ROS generation, redox imbalance and activation of stress-sensitive gene expression [24]. Unfortunately, when the supposed compensatory response (involving antioxidant enzymes such as catalase and other endogenous antioxidants including GSH, superoxide dismutase, GSH-Px) becomes inadequate to maintain redox equilibrium, oxidative stress ensues and results to cellular damage [24].

Furthermore, depletions of TAC in controlled T2DM and uncontrolled T2DM patients compared to healthy controls were equally observed in this study. This agrees with an earlier study [16]. Study shows that reduced antioxidant enzyme activities and TAC depletion may increase susceptibility of diabetics to oxidative injury [25]. Oxidative injuries have been repeatedly associated with development of complications in T2DM patients [24-27]. Abnormally high levels of free radicals, lipid peroxidation and simultaneous decline in antioxidant defense mechanisms are also deleterious to cellular organelles and enzymes. Effects of oxidative-antioxidative imbalance with potential oxidative injuries are commonly associated with diabetes, neurodegenerative disorders, cardiovascular diseases, and cancers [28].

On a separate note, although we observed strong positive associations between glycemic index and cholesterol level in both controlled and uncontrolled T2DM, there were divergent outcomes in total cholesterol levels between these two patient groups against the controls, respectively. Under controlled T2DM, TC was remarkably low against the healthy individuals while there was a high TC in uncontrolled T2DM patients. Our study partly suggests that there was a metabolic derangement in uncontrolled T2DM, which signified hypercholesterolemia. Although we did not assess proportions of lipoprotein particles, it has been suggested that hypercholesteremia is a hallmark of metabolic derangement in T2DM, which contributes to atherosclerosis through oxidative process [29]. On the other hand, in controlled T2DM our finding partly suggests that hypoglycemic agents inhibit cholesterol biosynthetic pathways that might be the culprit behind reduced TC level. In addition, in line with our finding, previous study reported inhibition of hepatocellular glucose, lipid and cholesterol biosynthetic pathways due to biguanide metformin treatment of T2DM by transcription ally suppressing steroid receptor coactivator 2 and in part activating the AMP-activated protein kinase pathway [30-32].

\section{CONCLUSION}

In this study, itis evident that both glycemic control with metformin and chronic hyperglycemia in uncontrolled T2DM have oxidative impacts on diabetics. However, the mechanism through which the anti-diabetic agents subject patients to oxidative stress is currently unknown. However, a recent report demonstrated that induction of oxidative stress in T2DM is not influenced solitarily by hyperglycemia but also by the categories of anti-diabetic drugs [20]. Our data, therefore, suggest that hypoglycemic agent (metformin) is associated with oxidative stress in the same way with chronic hyperglycemia; hence, glycemic 
control with metformin may not be considered to have meaningful effect to subdue oxidative stress but worsens it.

\section{NOTES}

Funding

This study did not receive financial support from outside sources.

\section{Conflicts of interest disclosure}

The authors declare no competing interests relevant to the content of this study.

\section{Authors' contributions}

All the authors declare to have made substantial contributions to the conception, or design, or acquisition, or analysis, or interpretation of data; and drafting the work or revising it critically for important intellectual content; and to approve the version to be published.

Availability of data and responsibility for the results

All the authors declare to have had full access to the available data and they assume full responsibility for the integrity of these results.

\section{REFERENCES}

1. Fakhruddin S, Alanazi W, Jackson KE. Diabetes-induced reactive oxygen species: mechanism of their generation and role in renal injury. J Diabetes Res. 2017;2017:8379327. https://doi.org/10.1155/2017/8379327

2. Sifuentes-Franco S, Padilla-Tejeda DE, Carrillo-Ibarra S, Miranda-Díaz AG. Oxidative stress, apoptosis, and mitochondrial function in diabetic nephropathy. Int J Endocrinol. 2018;2018:1875870. https://doi. org/10.1155/2018/1875870

3. Volpe CMO, Villar-Delfino PH, Dos Anjos PMF, Nogueira-Machado JA. Cellular death, reactive oxygen species (ROS) and diabetic complications. Cell Death Dis. 2018;9(2):119. https://doi.org/10.1038/s41419-017-0135-Z

4. Kitada M, Zhang Z, Mima A, King GL. Molecular mechanisms of diabetic vascular complications. J Diabetes Investig. 2010;1(3):77-89. https://doi.org/10.1111/j.2040-1124.2010.00018.x

5. Beckman JA, Creager MA. Vascular complications of diabetes. Circ Res. 2016;118(11):1771-85. https://doi. org/10.1161/circresaha.115.306884

6. Trinder P. Glucose assay: a colorimetric enzyme-kinetic method assay. Ann Clin Biochem. 1969;6:24.

7. Uloko AE, Musa BM, Ramalan MA, Gezawa ID, Puepet FH, Uloko AT, Borodo MM, Sada KB. Prevalence and risk factors for diabetes mellitus in Nigeria: a systematic review and meta-analysis. Diabetes Ther. 2018;9(3):1307-16. https://doi.org/10.1007/s13300-018-0441-1

8. American Diabetes Association. Classification and diagnosis of diabetes: standards of medical care in diabetes - 2018 . Diabetes Care. 2018;41(1):S13-S27. https://doi.org/10.2337/dc18-s002

9. Nathan DM, Singer DE, Hurxthal K, Goodson JD. The clinical information value of the glycosylated hemoglobin assay. N Engl J Med. 1984;310(6):341-6. https://doi.org/10.1056/nejm198402093100602

10. Varshney R, Kale RK. Effect of calmodulin antagonist on radiationinduced lipid peroxidation in microsomes. Int $\mathrm{J}$ Rad Biol. 1990;58(5):733-43.

11. Paglia DE, Valentine WN. Studies on the quantitative and qualitative characterization of erythrocyte glutathione peroxidase. J Lab Clin Med. 1967;70(1):158-69.

12. Aebi H. Catalase in vitro. Methods Enzymol. 1984;105:121-6.

13. Benzie IF, Strain JJ. The ferric reducing ability of plasma (FRAP) as a measure of "antioxidant power": the FRAP assay. Anal Biochem. 1996;239(1):70-6. https://doi.org/10.1006/abio.1996.0292

14. Allain CC, Poon LS, Chan CS, Richmond W, Fu PC. Enzymatic determination of total serum cholesterol. Clin Chem. $1974 ; 20(4): 470-5$

15. Kassaian SE, Goodarzynejad H, Boroumand MA, Salarifar M, Masoudkabir F, Mohajeri-Tehrani MR, Pourhoseini H, Sadeghian S, Ramezanpour N, Alidoosti M, Hakki E, Saadat S, Nematipour E. Glycosylated hemoglobin (HbA1c) levels and clinical outcomes in diabetic patients following coronary artery stenting. Cardiovasc Diabetol. 2012;11:82. https://doi.org/10.1186/1475-2840-11-82

16. Pieme CA, Tatangmo JA, Simo G, Nya PCB, Moor VJA, Moukette BM, Nzufo FT, Nono BLN, Sobngwi E. Relationship between hyperglycemia, antioxidant capacity and some enzymatic and non-enzymatic antioxidants in African patients with type 2 diabetes. BMC Res Notes. 2017;10:141. https://doi.org/10.1186/s13104-017-2463-6 
17. Yan LJ. Pathogenesis of chronic hyperglycemia: from reductive stress to oxidative stress. J Diabetes Res. 2014;2014:137919.

18. Wells-Knecht KJ, Zyzak DV, Litchfield JE, Thorpe SR, Baynes JW. Mechanism of autoxidative glycosylation: identification of glyoxal and arabinose as intermediates in the autoxidative modification of proteins by glucose. Biochemistry. 1995;34(11):3702-9. https://doi.org/10.1021/bi00011a027

19. Mishra S, Mishra BB. Study of lipid peroxidation, nitric oxide end product, and trace element status in type 2 diabetes mellitus with and without complications. Int J Appl Basic Med Res. 2017;7(2):88-93. https://doi.org/10.4103/2229516x.205813

20. ALrefai AA, Alsalamony AM, Fatani SH, Kamel HFM. Effect of variable antidiabetic treatments strategy on oxidative stress markers in obese patients with T2DM. Diabetol Metab Syndr. 2017;9:27. https://doi.org/10.1186/ s13098-017-0220-6

21. Aouacheri O, Saka S, Krim M, Messaadia A, Maidi I. The investigation of the oxidative stress-related parameters in type 2 diabetes mellitus. Can J Diabetes. 2015;39(1):4449. https://doi.org/10.1016/j.jcjd.2014.03.002

22. Góth L. Catalase deficiencyandtype 2 diabetes. Diabetes.Care 2008;31(12):e93.

23. Phaniendra A, Jestadi DB, Periyasamy L. Free radicals: properties, sources, targets, and their implication in various diseases. Indian J Clin Biochem. 2014;30(1):11-26. https://doi.org/10.1007/s12291-014-0446-0

24. Evans JL, Goldfine ID, Maddux BA, Grodsky GM. Oxidative stress and stress-activated signaling pathways: a unifying hypothesis of type 2 diabetes. Endocr Rev. 2002;23(5):599-622. https://doi.org/10.1210/er.2001-0039

25. Pendyala G, Thomas B, Joshi SR. Evaluation of total antioxidant capacity of saliva in type 2 diabetic patients with and without periodontal disease: a case-control study. N Am J Med Sci. 2013;5(1):51-7. https://doi.org/10.4103/19472714.106208

26. Asmat U, Abad K, Ismail K. Diabetes mellitus and oxidative stress-A concise review. Saudi Pharm J. 2015;24(5): 547-53. https://doi.org/10.1016/j.jsps.2015.03.013

27. Papatheodorou K, Banach M, Edmonds M, Papanas N, Papazoglou D. Complications of diabetes. J Diabetes Res. 2015;2015:189525. https://doi.org/10.1155/2015/189525

28. Srivastava KK, Kumar R. Stress, oxidative injury and disease. Indian J Clin Biochem. 2015;30(1):3-10.

29. Srivastava RAK. Life-style-induced metabolic derangement and epigenetic changes promote diabetes and oxidative stress leading to NASH and atherosclerosis severity. J Diabetes MetabDisord. 2018;17(2):381-91. https://doi. org/10.1007/s40200-018-0378-y

30. Madsen A, Bozickovic O, Bjune JI, Mellgren G, Sagen JV. Metformin inhibits hepatocellular glucose, lipid and cholesterol biosynthetic pathways by transcriptionally suppressing steroid receptor coactivator 2 (SRC-2). Sci Rep. 2015;5:16430. https://doi.org/10.1038/srep16430

31. Sliwinska A, Drzewoski J. Molecular action of metformin in hepatocytes: an updated insight. Curr Diabetes Rev. 2015; 11(3):175-81. https://doi.org/10.2174/1573399811666150325233108

32. van Stee MF, de Graaf AA, Groen AK. Actions of metformin and statins on lipid and glucose metabolism and possible benefit of combination therapy. Cardiovasc Diabetol. 2018;17(1):94. https://doi.org/10.1186/s12933-018-0738-4 